\title{
DE SCHRIJFDOOS HERFSTPLANTEN VAN DŌMOTO GOSABURŌ
}

De natuur vormt een onuitputtelijke bron van inspiratie voor Japanse lakkunstenaars; niet zozeer grootse landschappen of vergezichten, maar veeleer intieme plekjes of individuele bomen, planten of bloemen. Herfstplanten behoorden van oudsher tot de populairste onderwerpen. Vanwege de prachtige kleuren en het zonnige weer was de herfst voor veel mensen het meest geliefde seizoen. In de Japanse iconografie staan de Zeven Herfstplanten (aki no nanakusa) symbool voor geluk en een lang leven.

\section{Ontwerp}

Hoewel de traditionele iconografie in het begin van de $20^{\mathrm{c}}$ eeuw aan kracht had ingeboet bleven herfstplanten als onderwerp onverminderd populair. Dat is te zien op het deksel van de prachtige schrijfdoos, door Dömoto Gosaburō rond 1920 in Kyoto gemaakt (afb. 1). Het beeld wordt gedomineerd door de herfstbrem (Lespedeza bicolor Turcz. of hagi) met zijn tientallen koffieboonvormige blaadjes (steeds drie op een steeltje) en aan het uiteinde van de takken trosvormige bloemen. De takken van deze heester bepalen het ritme van de voorstelling. Daartussen zien we de ballonklokjes (Platycodon grandiflorum of kikyo) oplichten, omdat ze zijn ingelegd in stralend parelmoer. Bij verder speuren valt rechts onder het schermbloemige goudvaleriaan (Patrina Scabiosifolia L. of ominaeshi) te ontdekken en vlak daarbij enkele zilveren pluimen van het prachtriet (Miscanthus sinensis of suzuki). Deze aangename wirwar van planten zet zich over de randen voort naar de zijkanten links en onder, waar het gewas nog dichter lijkt te groeien. De continuiteit van het overlopende beeld wordt bevorderd door de lichtjes aflopende randen van het deksel en door de afgeronde hoeken. Het ontwerp is sterk asymmetrisch met het zwaartepunt in de linker onderhoek.

Het vlak van het deksel wordt in tweeën gedeeld door een schuin weglopend beekje. Daarachter strekt zich een vlakte uit die begroeid is met pollen van het rijzige prachtriet.

Het gouden beekje ligt enigszins verzonken in de zwarte ondergrond en de oevers zijn opvallend bestrooid met goudpoeder. Het moet wel om een nachtelijke scène gaan, waardoor het beekje ligt te spiegelen in het maanlicht en de ballonklokjes zo opvallend oplichten tussen de herfstbrem.

De binnenkant van de schrijfdoos contrasteert in meer dan één opzicht met de buitenkant. Het gaat daar niet om de weergave van een plekje in de natuur, maar om willekeurig uitgestrooide plukjes kersenbloesem (afb. 2). Dus: een lentemotief als tegenhanger voor de verbeelding van de herfst op de buitenkant. Ook de zilveren waterdruppelaar heeft de vorm van een kersenbloesem. De titel van de schrijfdoos, die met inkt op het deksel van de houten verpakkingsdoos geschreven staat, luidt: "makie schrijfdoos Herfstplanten". 

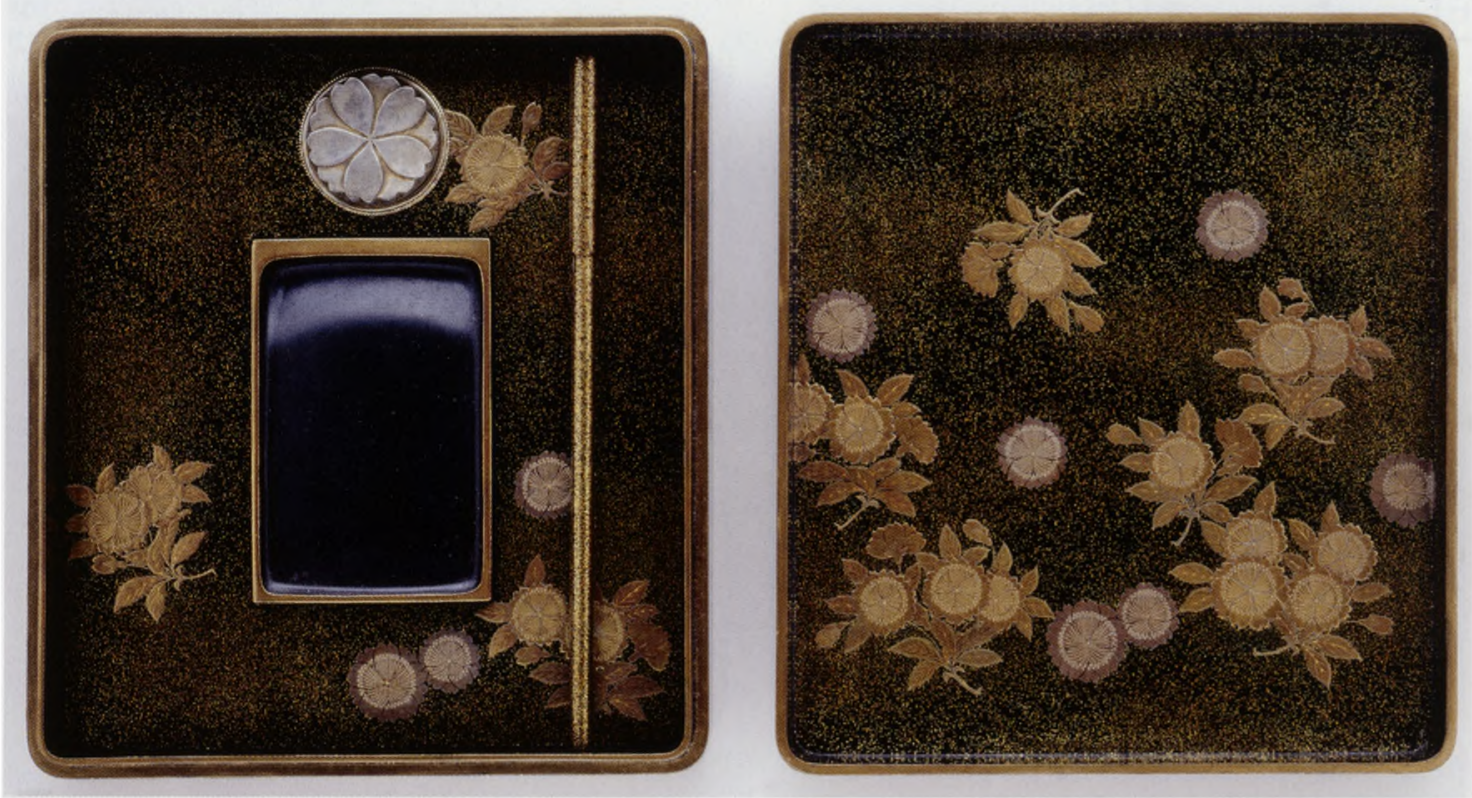

Afb. 2

Geopende schrijfdoos met waterdruppelaar, penseel en inktsteen. De binnenkant is versierd met uitge. strooide plukjes kersenbloesem.

\section{Laktechnieken: de principes van 'makie'}

Deze schrijfdoos is gemaakt in de meest karakteristieke van alle Japanse laktechnieken: makie of 'gesprenkeld beeld'. Dit wil zeggen dat de decoratie tot stand komt door het sprenkelen van goud- of zilverpoeder in de nog niet uitgeharde lak.

Dat gaat als volgt in zijn werk. Allereerst wordt de ontwerptekening op half transparant papier aan de achterzijde overgetrokken met een dunne penseel gedoopt in ijzerrode lak. De natte kant van het papier wordt dan op de reeds afgewerkte ondergrond van de lakdoos afgedrukt. Deze rode laktekening vormt nu de leidraad voor de uitwerking van de lakdecoratie. De omtrek van een blad of bloem kan worden ingevuld met rode of transparante lak en vervolgens worden besprenkeld met goud- of zilverpoeder (of -snippers). Het instrumentje dat hiervoor wordt gebruikt heet tsutsu: een hol bamboe buisje dat aan één kant is voorzien van een zijden gaasje, dat helpt bij de spreiding van de poeder tijdens het uitstrooien (afb. 3). Voor het begrip van makie zijn drie technieken van wezenlijk belang (afb. 4):

\section{1. hiramakie ('vlak reliëf'). Voor het uitbeelden van een blad of bloem zijn} meerdere lagen nodig om voldoende dekking en kleurintensiteit te verkrijgen. Dat komt doordat alleen een hele dunne laklaag goed kan uitharden en daarom is de hoeveelheid uit te strooien metaalpoeder in één enkele laag beperkt. Elke laag moet opnieuw uitharden en vervolgens met een slijpsteentje worden geschuurd voordat de nieuwe laag kan worden opgebracht. Pas zo ontstaat een stralend gouden oppervlak. De onderliggende lagen bepalen mede het uiteindelijke effect; zo versterkt een rode basislaag de intensiteit van de goudkleur aan het oppervlak, al liggen er drie (flinterdunne) gouden laklagen bovenop. Omdat het bij hiramakie om meerdere laklagen gaat, is deze vlakke decoratie toch juist met de vinger voelbaar. 
Afb. 3

Tsutsu: het buisje (hier niet van bamboe, maar van aluminium) met een stukje zijdegaas aan het uiteinde, waarmee metaalpoeder of metaalvlokjes in de nog niet uitgeharde lak wordt uit gesprenkeld door met de ringvinger tegen het buisje te tikken.

Afb. 4

Overzicht van de drie belangrijkste makie technieken.

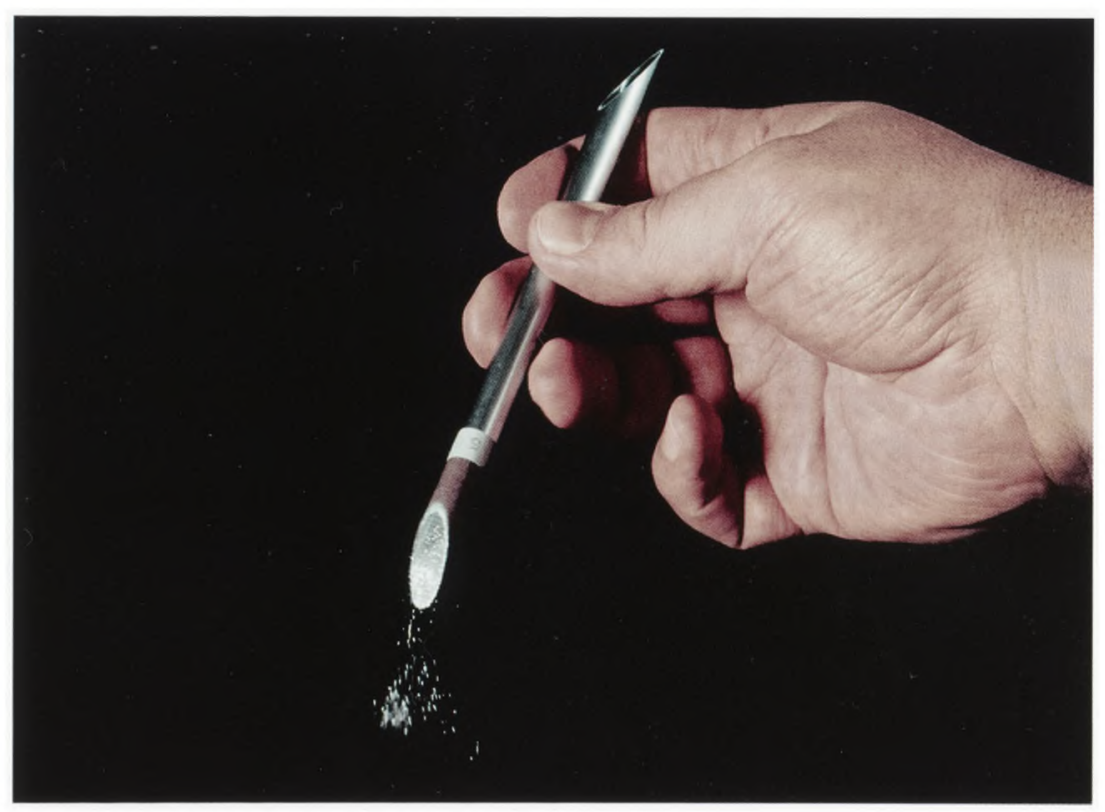

a. hiramakie

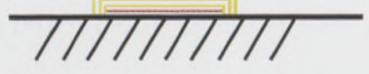

b. togidashi

Slijpsteentje
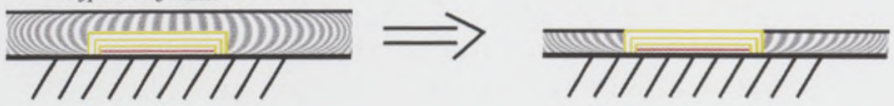

c. takamakie

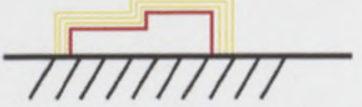

2. togidashi ('uitgeslepen decoratie'). Hierbij wordt eerst de procedure van hiramakie gevolgd. Vervolgens wordt de zojuist voltooide hiramakie decoratie volledig bedekt met een laag zwarte lak (dan wel met rood of goud naar gelang de kleur van de ondergrond). Na het uitharden wordt het zwarte oppervlak zolang met polijststeentjes geslepen tot de decoratie juist aan het oppervlak komt. Bij togidashi ligt de decoratie niet óp, maar ín de ondergrond en daarom is ze niet voelbaar met de vinger. Omdat de randen van de afbeelding iets onscherp zijn en de kleur iets minder intens is roept togidashi vaak de indruk van afstand of diepte op; soms wordt er ook een dromerig effect mee bereikt. 
3. takamakie (hoog reliëf). Hierbij wordt dezelfde procedure gevolgd als voor hiramakie, maar pas nadat er een aantal extra onderlagen van lak vermengd met gedroogde kleipoeder of lak met houtskoolpoeder zijn aangebracht die louter dienen om een sculpturaal effect te verkrijgen. Het reliëf is goed zichtbaar en voelbaar.

\section{Laktechnieken: 'makie' op de doos 'Herfstplanten'}

Op de schrijfdoos Herfstplanten heeft Dōmoto Gosaburō op meesterlijke wijze gebruik gemaakt van de combinatie van hiramakie en togidashi (takamakie komt op deze doos niet voor). Wanneer wij de wirwar van planten op het deksel meer in detail bekijken is duidelijk te zien dat sommige blaadjes en bloemen van de herfstbrem in licht reliëf zijn aangebracht en als het ware óp het deksel liggen, terwijl andere blaadjes en bloemen op gelijk vlak met de ondergrond liggen en daardoor op iets grotere afstand van de kijker (afb. 5). Zo ontstaat de illusie van diepte.

Vanwege het slijpproces met steentjes moet de decoratie hier wel in twee fases

Afb. 5

Detailopname van het deksel. tot stand zijn gekomen: eerst het togidashi-gedeelte en pas daarna het hiramakiegedeelte. Vermoedelijk moet dan ook de ontwerptekening in twee stappen op de ondergrond zijn afgedrukt: eerst het gedeelte dat bedoeld was om in

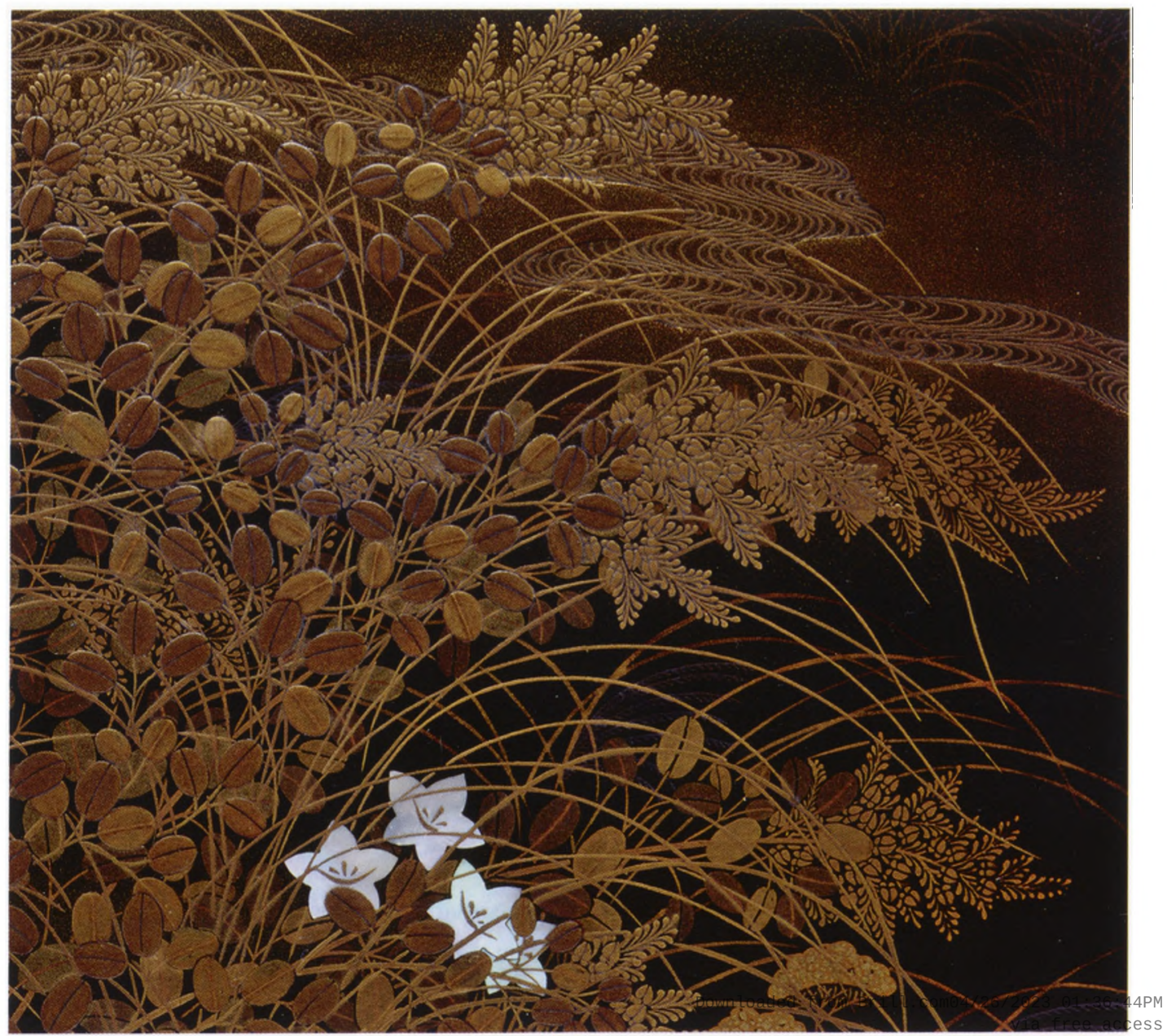


togidashi uit te beelden; pas na de voltooiing van deze decoratiefase kon het gedeelte dat bedoeld was om in hiramakie uit te beelden worden afgedrukt. Bovendien speelt Gosaburō met verschillende tinten goud. Voor het hiramakie-gedeelte van de blaadjes heeft hij een wat bruinere en een wat gelere goudtint uitgekozen. De bruinige blaadjes zijn voorzien van een groefje in het midden en representeren daarom de bovenkant, terwijl er bij de gelige blaadjes een verhoogd streepje over het midden loopt wat de uitloper van het steeltje aan de onderkant van het blad vertegenwoordigt. Een vergelijkbaar effect heeft de kunstenaar in de togidashi-fase bereikt door gebruik te maken van een donkere zilvergouden tint en een lichte groengouden tint.

Niet alleen een gedeelte van de blaadjes van de herfstbrem, maar ook de pluimen van het prachtriet en een deel van de grassprieten zijn in togidashi uitgevoerd. Het verschil tussen hiramakie en togidashi is in afbeelding $\mathbf{5}$ bijzonder goed te zien in de trosvormige bloemen van de herfstbrem, die elkaar gedeeltelijk overlappen. Iets meer naar boven valt bovendien op dat het beekje niet óp of ín het niveau van de ondergrond ligt, maar juist enigszins verzonken. Dit verzonken beekje moet Gosaburō al tijdens de opbouw van de vele lagen van de ondergrond hebben uitgespaard.

Achter het beekje ligt de vlakte met de pollen prachtriet, die niet in hiramakie of togidashi zijn afgebeeld, maar met een dun penseeltje zijn geschilderd. Omdat een enkele laklaag slechts een beperkte hoeveelheid goud- of zilverpoeder kan bevatten is het dekkende vermogen ervan beperkt. Daardoor lijkt het prachtriet doorzichtig te zijn, wat goed past in het beeld van afstand aan de overkant van het beekje.

Dan is er ook nog de binnenkant, waarover in technisch opzicht minder valt op te merken. De plukjes kersenbloesem zijn allemaal uitgevoerd in gedetailleerd zilver en goud hiramakie. De ondergrond is bestrooid met goudsnippers die zich hier en daar verdichten tot 'wolken'.

\section{Dōmoto Gosaburō}

De signatuur 'Gosaburō' zit verstopt onder de inktsteen. Deze naam helpt enigszins bij de datering van de schrijfdoos, omdat de kunstenaar deze na 1935 niet meer gebruikte. Nadien was hij in de kunstgeschiedenis bekend onder de naam Dömoto Shikken (1889-1964). Hij nam deel aan de nationale kunsttentoonstellingen Teiten, Shin-Bunten en Nitten. In zijn werk valt een duidelijke ontwikkeling waar te nemen van tamelijk traditioneel Japans (zoals in deze schrijfdoos) tot Art Deco en modernere stijlen. Gosaburō bewoog zich in de vooruitstrevende kunstenaarskringen in Kyoto in de periode tussen de beide wereldoorlogen, waarvan niet alleen lakkunstenaars als Kōda Shüetsu (1881-1933), Tojima Kōfu (1882-1956), Shōgō Banura (1901-1982) en Suzuki Hyōsaku II (1905-1943) deel uitmaakten, maar ook de beroemde ontwerper Kamisaka Sekka (1866-1942) en Gosaburö's jongere broer, de vooraanstaande schilder Dömoto Inshō (1891-1975).

De schrijfdoos Herfstplanten moet juist vóór de periode van ingrijpende modernisering van de lakkunst zijn gemaakt, wellicht rond 1920.

- In 1975 raakte Jan Dees geboeid door de lakkunst van Japan. Sinds de late jaren 80 verricht hij onderzoek naar lakkunstenaars uit de periode 1890-1950. Hieruit is in 2007 het proefschrift Facing Modern Times: The revival of Japanese lacquer art 1890-1950 voortgekomen. 


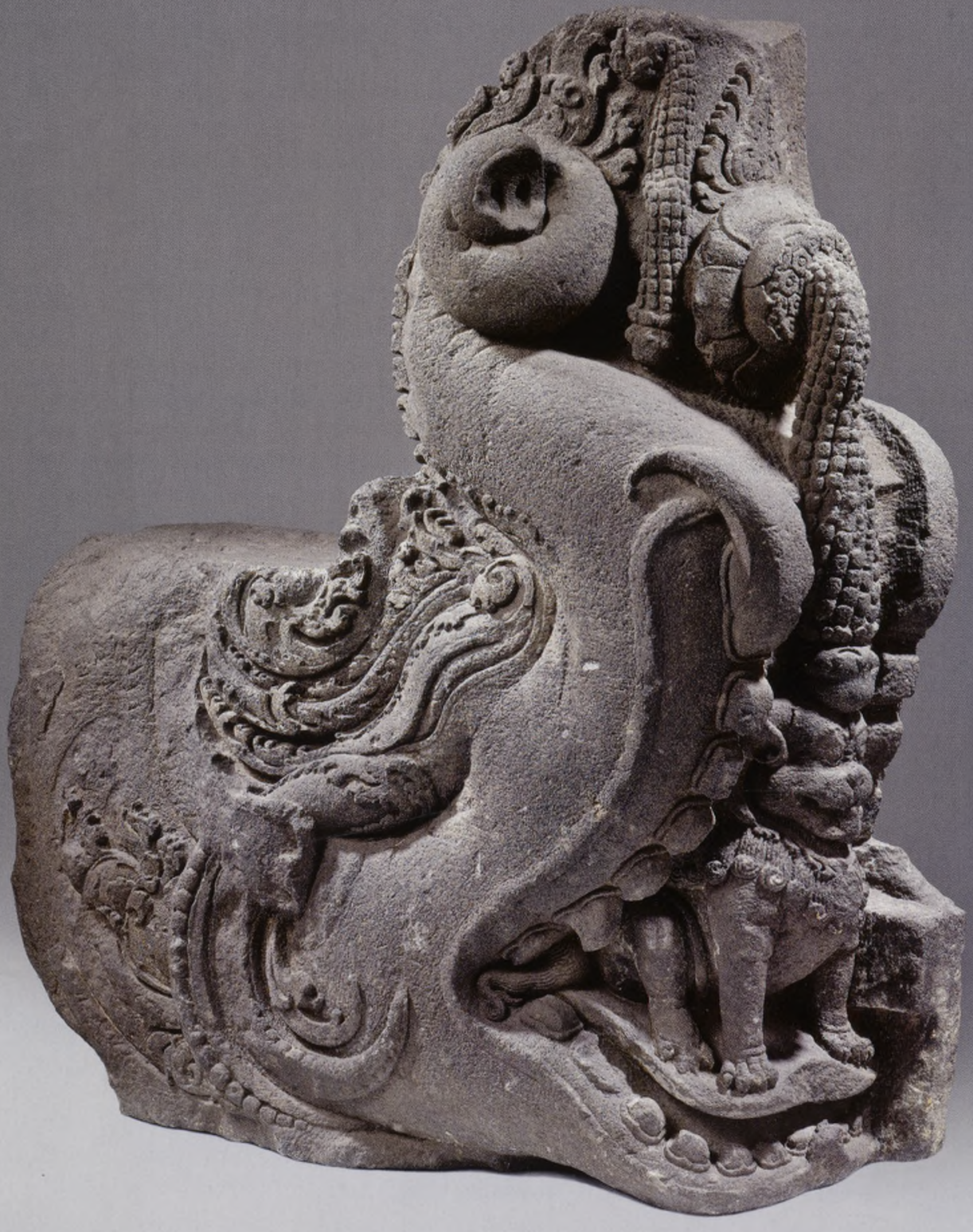

Fig. 1

Makara, stone, h. $97 \mathrm{~cm}$., Indonesia, 9th century, Rijksmuseum, AK-MAK-247, side view. Photograph: Rijksmuseum Amsterdam. 